\title{
LA URGENTE TAREA DE RESITUAR LA COMPLEJDAD DISCIPLINAR
}

\section{[EN] THE URGENT TASK OF RESTORING DISCIPLINARY COMPLEXITY}

La urgencia de resituar la complejidad disciplinar en el Trabajo Social alude a no enfocar el esfuerzo intelectual hacia cómo pensar en Trabajo Social, sino sobre qué pensar, es decir, sobre lo que acontece. El qué pensar se traduce en la oportunidad de forjar llaves que nos permitan abrir cerrojos que se empeñan en cerrar las puertas y mantener presa la tarea de hermanar la ciencia, filosofía y su fundamento material de la sociedad. Pensar sobre lo que acontece nos remite a una observación y configuración cartográfica del entendimiento considerando lo cotidiano. Esto, a la luz de Yáñez (2015), será caracterizado por "percibir, identificar, describir, explicar, interpretar e intervenir sobre una multiplicidad de objetos constitutivos de ese mismo mundo" (p. 3). Es decir, desde un pensamiento complejo, uno que asume la múltiple composición de lo social, con una contextura que se arma una y otra vez.

Un pensamiento complejo disciplinar implica generar una capacidad iluminadora y responsiva a la adversidad, pero en consideración de un tejido de la realidad social que se constituye en y por la incertidumbre, asociación, recursividad e interseparabilidad (Morin, 2001). Desde esta perspectiva, veremos que la expresión de lo que pensamos y hacemos en el Trabajo Social también se encuentra circunscrita por esa misma realidad: conflictiva, 
interdependiente, caleidoscópica, aleatoria y con una multiplicidad de relaciones e interacciones. Es decir, e interpretando a la luz de Morin y Kern (1993), nos encontramos en la confluencia de una diversidad de asuntos complementarios/antagónicos. Esto es nuestro mundo fenoménico.

En rigor nuestra realidad social nos llama a la tarea de construir una complejidad disciplinar capaz de conducirse por la aprehensión del conocimiento múltiple referencialidad. Un conocimiento que relaciona lo constitutivo y constituido por los signos, lenguaje y códigos sociales de nuestro mundo fenoménico. Precisamente, es ante esta tarea que la Revista Voces desde el Trabajo Social traza como ruta intelectual urdir los diversos regímenes de pensamientos y perspectivas, pero en disposición a contrastarse con la experiencia del mundo social. De igual forma, nuestra revista busca contribuir a la apertura de caminos que ayuden a transcender la falacia que habla sobre la preeminencia de la teoría sobre la experiencia o, bien, de la experiencia sobre los enunciados y reflexiones. Finalizo, hemos hablado de que el propio acto de conocer es complejo. La tarea de resituar la complejidad disciplinar conlleva hermanar lo teórico y lo empírico, puesto que en su caso contrario y parafraseando a Foucault (1995), nos encontraríamos contenidos por palabras mudas y acciones adormecidas. 


\section{Referencias}

Foucault, M. (1995). Las palabras y las cosas: Una arqueología de las ciencias humanas. México: Siglo XXI.

Morin, E. (2001). La mente bien ordenada: Repensar la reforma.

Reformar el pensamiento. Barcelona: Seix Barral.

Morin, E., \& Kern, A. (1993). Tierra-Patria. Barcelona: Kairós.

Yánez, V. (2013). Notas sobre la complejidad del Trabajo Social:

Develación de la densa trama entre nuestras observaciones, gramaticalidades y debates disciplinarios. Revista Electrónica de Trabajo Social, 9(1), 1-13.

\section{Eduardo Zavala-Mendoza}

Editor General del Colegio de Profesionales del Trabajo Social de Puerto Rico /

Instructor en la Universidad de Puerto Rico, Recinto de Río Piedras. Director de Planificación y Desarrollo en la Secretaría Auxiliar de Planificación, Desarrollo y Asuntos Federales del

Departamento de Salud de Puerto Rico.

$\triangle$ eduardo.zavala@upr.edu

(D) ORCID ID https://orcid.org/0000-0002-1909-7856 